\title{
In situ detection of bacteria in continuous-flow cultures of seawater sediment suspensions with fluorescently labelled rRNA-directed oligonucleotide probes
}

\author{
Alke Bruns and Luise Berthe-Corti \\ Author for correspondence: Luise Berthe-Corti. Tel: +441 7983290. Fax : +4417983250.
}

Fachbereich Biologie, C.v.O. Universităt Oldenburg, PO Box 2503, D-26111 Oldenburg, Germany

\begin{abstract}
rRNA-targeted and fluorescently labelled oligonucleotide probes were used to study the composition of natural bacterial populations in continuous-flow cultures of seawater sediment suspensions. The cultures were run as enrichment cultures with increasing dilution rates, and hexadecane as the sole carbon source. Total cell numbers were analysed by counting DAPI (4',6diamidino-2-phenylindole)-stained cells. To differentiate the population composition, oligonucleotide probes for eubacteria, for Cytophaga/ Flavobacteria, and for four subclasses of the Proteobacteria $(\alpha, \beta, \gamma$ and $\delta)$ were used. About $40-80 \%$ of the DAPI-stained cells could be detected with the EUB338 probe. Moreover, it was possible to detect a shift in the composition of the natural bacterial population with increasing dilution rate of the continuous culture, from large amounts of Cytophaga/Flavobacteria to large numbers of members of the $y$-Proteobacteria. The cell recovery rate for bacteria labelled with specific oligonucleotide probes was analysed with defined cell numbers of Rhodospirillum rubrum, Comamonas testosteroni and Desulfovibrio vulgaris subsp. vulgaris introduced into the seawater sediment suspension, and was determined to be $13 \cdot 9-33.5 \%$. The standard deviation determined for this method applied to sediment suspensions was $\pm 8.3 \%$. The results suggest that the application of the in situ hybridization technique allows a good insight into the structure of populations growing in sediment suspensions.
\end{abstract}

Keywords: in situ hybridization, rRNA-targeted oligonucleotide probes, intertidal sediment suspension, population structure

\section{INTRODUCTION}

Bioremediation processes performed by mixed populations are very important in the ecology of marine environments. The biodegradation of hydrocarbons like hexadecane (a compound of mineral oil) is of particular interest since bioremediation is the most important natural process in the removal of oil pollution in marine ecosystems (Radwan \& Sorkhoh, 1993; Leahy \& Colwell, 1990). Up to now, diversity and population structures of marine sediments have mostly been analysed by culture-dependent methods like the c.f.u. (colony-forming units), and MPN (most probable num-

Abbreviations: Dabco, 1,4-diazabicyclo[2.2.2]octane; DAPI, 4',6diamidino-2-phenylindole; MPN, most probable number. ber) techniques, the Biolog-System (Fredrickson et al., 1991; Rüger \& Krambeck, 1994), and fatty acid analysis (Oliver \& Colwell, 1973). However, it has been increasingly appreciated that methods based on cultivation in the laboratory are always selective and therefore cannot yield sufficient information on the actual community structure (Snaidr et al., 1997). Moreover, these methods only detect a low percentage of the true numbers of bacteria (Staley \& Konopka, 1985; Ward et al., 1990) and neglect the so-called viable but non-culturable micro-organisms (Roszak \& Colwell, 1987; McKay, 1992). Recent investigations have demonstrated that nutrient-rich media, which were used mainly for the c.f.u. and MPN methods, favoured growth of $\gamma$-Proteobacteria (e.g. Acinetobacter) and suppressed $\beta$-Proteobacteria. The latter were underestimated by cultivation techniques but could be 
visualized by in situ hybridization (Wagner et al., 1993; Manz et al., 1994).

In recent years an in situ hybridization technique has been developed which allows direct demonstration of micro-organisms in situ (Amann et al., 1995). In the study described here we used this technique to characterize the microbial hexadecane-degrading community active in an intertidal-sediment suspension culture. The aim was to test whether this method could be used for the differentiation of the indigenous population in such cultures. The applicability of this technique to hitherto uncultured bacteria has already been demonstrated (Spring et al., 1992; Amann et al., 1991) and thus we expected to gain a comprehensive overview of the natural community structure in our culture of seawatersediment suspensions.

\section{METHODS}

Sampling. Samples were collected from a continuous-flow culture containing a suspension of intertidal sediment from the German North Sea coast $(11 \%, w / v)$ with hexadecane as the sole carbon source (Berthe-Corti et al., 1997). The culture was run for $900 \mathrm{~h}$. After an initial batch phase of $48 \mathrm{~h}$, the dilution rate $(D)$ was increased stepwise from 0.008 to $0.047 \mathrm{~h}^{-1}$. Each $D$ was kept constant for at least $70 \mathrm{~h}$. The storage tank contained a sterile sediment suspension with hexadecane as the sole carbon source $\left(0.8 \mathrm{~g} \mathrm{l}^{-1}\right)$. The culture was inoculated with fresh intertidal sediment. At three different dilution rates $\left(D=0.008,0.015\right.$ and $\left.0.047 \mathrm{~h}^{-1}\right)$, three samples, each with a volume of $15 \mathrm{ml}$, were collected.

In situ hybridization. The suspension samples were prepared immediately for in situ hybridization to avoid loss of cell activity. Samples $(2 \mathrm{ml})$ of the sediment suspension were mixed with $10 \mu \mathrm{l}$ sterile Tween 80 (final concentration $0.05 \%$ $\mathrm{v} / \mathrm{v}$ ) and sonified in an ice-cold $10 \mathrm{ml}$ plastic tube for $3 \times 30 \mathrm{~s}$ at $30 \mathrm{~W}$ with a Branson Sonifier B12.

The sediment preparation was subsequently diluted $1: 100$, 1:50 and $1: 10$ with $0.9 \%(\mathrm{v} / \mathrm{v}) \mathrm{NaCl}$. Three microlitres of these dilutions were applied in duplicate to wells of gelatincoated slides $\left[0.1 \%\right.$ gelatin, $0.01 \% \mathrm{KCr}\left(\mathrm{SO}_{4}\right)_{2}$ (Jürgens)] and allowed to air-dry. After dehydration by consecutive immersion for $3 \mathrm{~min}$ each in 50, 80, and $96 \%(\mathrm{v} / \mathrm{v})$ ethanol, hybridization was performed in $7 \mu$ l hybridization buffer $(35 \%$ formamide, $0.9 \mathrm{M} \mathrm{NaCl}, 10 \mathrm{mM}$ Tris/HCl, $0.01 \%$ SDS, $\mathrm{pH}$ $7.4)$ with $0.75 \mu$ l oligonucleotide probe solution $\left(100 \mu \mathrm{g} \mathrm{m}^{-1}\right)$ at $48{ }^{\circ} \mathrm{C}$ for $60 \mathrm{~min}(1.5 \mu \mathrm{l}$ probe ALF1b was applied in $7 \mu$ l hybridization buffer). The hybridization procedure was carried out in carefully sealed moisture chambers to prevent evaporative loss of hybridization solution (Wallner \& Amann, 1993). After hybridization, the slides were washed in a buffer containing $40 \mathrm{mM} \mathrm{NaCl}, 20 \mathrm{mM}$ Tris/ $\mathrm{HCl}$ and $0.01 \%$ (w/v) SDS for $20 \mathrm{~min}$ at $48{ }^{\circ} \mathrm{C}$, rinsed with Millipore water and air-dried.

Oligonucleotide probes. We used six rRNA-targeted oligonucleotide probes labelled with the fluorescent dye Cy3 (Interactiva) (Table 1). The ALF1b probe was used in a mixture (1:1) of two oligonucleotide sequences: one with a thymine and one with a cytosine for binding in position 29 (Brosius et al., 1981). Probes BET42a and GAM42a rely on the discrimination of a single mismatch and were therefore used with competitor oligonucleotides as described earlier (Manz et al., 1992; Wagner et al., 1994). The eubacterial probe EUB338 served as a positive control to test the efficiency of the hybridization.

Dual staining with DAPI. After hybridization, the dry slide preparations were covered with $4 \mu \mathrm{l}$ of an anti-fading medium. This medium consists of a 1:1 mixture of DAPI solution $(1 \mu \mathrm{g}$ 4',6-diamidino-2-phenylindole $\mathrm{ml}^{-1}$ ) and Dabco solution (25 mg 1,4-diazabicyclo[2.2.2] octane in $1 \mathrm{ml}$ PBS buffer and $9 \mathrm{ml}$ glycerin). The preparations were examined with a Zeiss Axioskop equipped for detecting epifluorescence with a $50 \mathrm{~W}$ mercury high-pressure bulb and filter sets 01 (excitation $365 \mathrm{~nm}$, emission $397 \mathrm{~nm}$ ) and 15 (excitation $546 \mathrm{~nm}$, emission $590 \mathrm{~nm})$. Each well $(6 \mathrm{~mm}$ diameter) of the slides was subdivided into nine fields. The cells in these fields were counted and the cell concentrations were calculated as follows:

Cells $\mathrm{ml}^{-1}=N_{\mathrm{m}} \times 2 \cdot 48 \times 10^{5} \times$ dilution factor

where $N_{\mathrm{m}}$ is the mean value of cell numbers counted in the nine fields. The factor $2.48 \times 10^{5}$ results from the fact that only $3 \mu \mathrm{l}$ of the diluted samples was applied to each well $\left(333 \mathrm{ml}^{-1}\right)$. Furthermore, it takes into account the relation of the area of the slide well $\left(28274334 \mu \mathrm{m}^{2}\right)$ to the area of one counted field at an enlargement of $1000 \times\left(38013.271 \mu \mathrm{m}^{2}\right)$.

To avoid errors caused by sediment particle autofluorescence, only cells stained dually with DAPI and Cy3 were accepted in calculating the hybridization efficiency. For this, the fluorescence of each cell in a field was observed with the filter set 01 , whereby the DAPI-stained cells gave a blue epifluorescent signal, and with the filter set 15 , whereby hybridized cells show a red epifluorescent signal only with the specific probe (see Fig. 1). It must be noted that the microscopic images were of much higher quality (cells give sharp spots) than the photographic reproductions. Due to the very small cell sizes the intensity of the fluorescent signals was low and required long exposure times, which caused blurred images.

Checking of probes. The hybridization efficiency of the purchased oligonucleotides was estimated using pure cultures of phylogenetically corresponding organisms by whole-cell hybridization. For this, the strains listed in Table 2 were cultivated on complex media, and $3 \mu \mathrm{l}$ of a liquid culture or of a cell suspension $(0.9 \% \mathrm{NaCl})$ was applied to slides and allowed to air-dry. After dehydration in a series of ethanol baths the samples were hybridized under the conditions described above.

Detection of defined cell numbers of bacteria in intertidal sediment suspension. A mud-flat sediment suspension was inoculated with defined cell numbers (determined by DAPI staining) of the phylogenetically different bacteria Rhodospirillum rubrum, Comamonas testosteroni and Desulfovibrio vulgaris subsp. vulgaris. The sediment in the suspension before inoculation was treated as follows: from heat-treated dry sediment $\left(180^{\circ} \mathrm{C}\right.$ for $\left.12 \mathrm{~h}\right)$, a suspension $(11 \%, w / v)$ with artificial seawater (according to Grasshoff, 1983) was prepared and autoclaved twice at $121^{\circ} \mathrm{C}$ for $20 \mathrm{~min}$. After inoculation, the sediment suspension was incubated for $30 \mathrm{~min}$ at $5{ }^{\circ} \mathrm{C}$ to allow the cells introduced to bind to sediment particles. Samples $(2 \mathrm{ml})$ of this incubated sediment suspension were hybridized as described above.

\section{RESULTS}

\section{Applicability of the probes}

The purchased fluorescently labelled oligonucleotides were applied to their group-specific micro-organisms by 
Table 1. Sequences, target position and specifications of rRNA-directed and fluorescently labelled oligonucleotide probes used for whole-cell and in situ hybridization

\begin{tabular}{|c|c|c|c|c|}
\hline Probe & Sequence $\left(5^{\prime}-3^{\prime}\right)$ of probe & $\begin{array}{l}\text { Target position } \\
\text { (rRNA) }\end{array}$ & Specificity & Reference \\
\hline EUB338 & GCT GCC TCC CGT AGG GAG T & $16 S, 338-355$ & Bacteria & $\begin{array}{l}\text { Amann et al. } \\
\text { (1990a) }\end{array}$ \\
\hline ALF1b & CGT TCG YTC TGA GCC AG & $16 S, 19-35$ & $\begin{array}{c}\alpha \text {-Proteobacteria, several members of } \\
\delta \text {-Proteobacteria, most spirochaetes }\end{array}$ & Manz et al. (1992) \\
\hline BET42a & GCC TTC CCA CTT CGT TT & $23 S, 1027-1043$ & $\beta$-Proteobacteria & Manz et al. (1992) \\
\hline GAM42a & GCC TTC CCA CAT CGT TT & $23 S, 1027-1043$ & $\gamma$-Proteobacteria & Manz et al. (1992) \\
\hline SRB385 & CGG CGT CGC TGC GTC AGG & $16 \mathrm{~S}, 385-402$ & Most members of $\delta$-Proteobacteria & $\begin{array}{l}\text { Amann et al. } \\
(1990 \mathrm{~b}, 1995)\end{array}$ \\
\hline CF319a & TGG TCC GTG TCT CAG TAC & $16 S, 319-336$ & $\begin{array}{l}\text { Most members of Cytophaga/ } \\
\text { Flavobacterium cluster of CFB } \\
\text { phylum, few Gram-positive } \\
\text { bacteria }\end{array}$ & Manz et al. (1996) \\
\hline
\end{tabular}

* E. coli numbering according to Brosius et al. (1981).

whole-cell hybridization. The results presented in Table 2 indicate an intense hybridization signal with the probes BET42a, GAM42a, SRB385 and CF319a. However, the probe ALF1b only showed a moderate to weak fluorescent signal. This could be explained by the nonoptimal hybridization conditions for this probe $(35 \%$ formamide instead of $20 \%$ as recommended by Manz et al., 1992). Analysing several samples of the sediment suspension in parallel directly after they were taken made an optimal treatment of each probe too costly in man-hours and material. Hence we accepted suboptimal hybridization conditions for the probe ALF1b.

\section{Recovery of defined cell numbers in the sediment suspension}

To test the recovery rate, a sterile sediment suspension was spiked with defined cell numbers of three different bacterial strains (Table 3). The suspension was applied to slides and hybridization with the corresponding group-specific probe was performed. Recovery rates of the cells introduced varied between $13.9 \%$ and $33.5 \%$ (Table 3). These decreased cell numbers were obtained after the in situ hybridization process. Comparing the number of DAPI-stained cells in the suspension before and after the in situ hybridization procedure, we recovered only $30-70 \%$ of the cells initially present after the hybridization (data not presented). That means that the hybridization procedure caused a loss of bacterial cell numbers. For Rbodospirillum rubrum only $19.9 \%$ of the spiked cells were recovered, and for Comamonas testosteroni only $13.9 \%$ (Table 3 ). This is due to the losses incurred during the hybridization procedure and also to the inactive cells in the inoculum which cannot be hybridized. The inoculum of the Desulfovibrio vulgaris subsp. vulgaris strain was characterized by more active

Table 2. Hybridization results (whole-cell hybridization) with reference organisms belonging to specific phylogenetic groups

\begin{tabular}{|llll|}
\hline Organism & \multicolumn{1}{c}{ Phylogenetic group } & Source/strain* & $\begin{array}{c}\text { Hybridization } \\
\text { signal with } \\
\text { specific probe }\end{array}$ \\
\hline Rhodospirillum rubrum & $\alpha$-Proteobacterium & DSMZ 467 & Weak \\
Rhodopseudomonas palustris & $\alpha$-Proteobacterium & DSMZ 123 & Moderate \\
Comamonas testosteroni & $\beta$-Proteobacterium & DSMZ 50244 & Strong \\
Escherichia coli & $\gamma$-Proteobacterium & DSMZ 613 & Strong \\
Desulfovibrio vulgaris subsp. & $\delta$-Proteobacterium & DSMZ 2119 & Strong \\
vulgaris & & DSMZ 1382 & Strong \\
Desulfovibrio gigas & $\delta$-Proteobacterium & DSMZ 1132 & Strong \\
Flavobacterium aquatile & Cytophaga/Flavobacterium & & \\
\hline
\end{tabular}

*DSMZ, Deutsche Sammlung von Mikroorganismen und Zellkulturen, Braunschweig, Germany. 
Table 3. Recovery of defined cell numbers in a sediment suspension by in situ hybridization with probes ALF1b (detecting Rhodospirillum rubrum), BET42a (detecting Comamonas testosteroni) and SRB385 (detecting Desulfovibrio vulgaris)

\begin{tabular}{|c|c|c|c|}
\hline \multirow[t]{2}{*}{ Organism } & \multicolumn{2}{|c|}{$\begin{array}{l}10^{-6} \times \text { No. of cells ml } \mathrm{l}^{-1} \text { in } \\
\text { sediment suspension }\end{array}$} & \multirow[t]{2}{*}{$\begin{array}{c}\text { Recovery } \\
(\%)\end{array}$} \\
\hline & Inoculated & Recovered & \\
\hline Rhodospirillum rubrum & $1 \cdot 39$ & $0 \cdot 273$ & $19 \cdot 6$ \\
\hline Comamonas testosteroni & 8.95 & $1 \cdot 24$ & 13.9 \\
\hline Desulfovibrio vulgaris & $6 \cdot 2$ & $2 \cdot 08$ & $33 \cdot 5$ \\
\hline
\end{tabular}
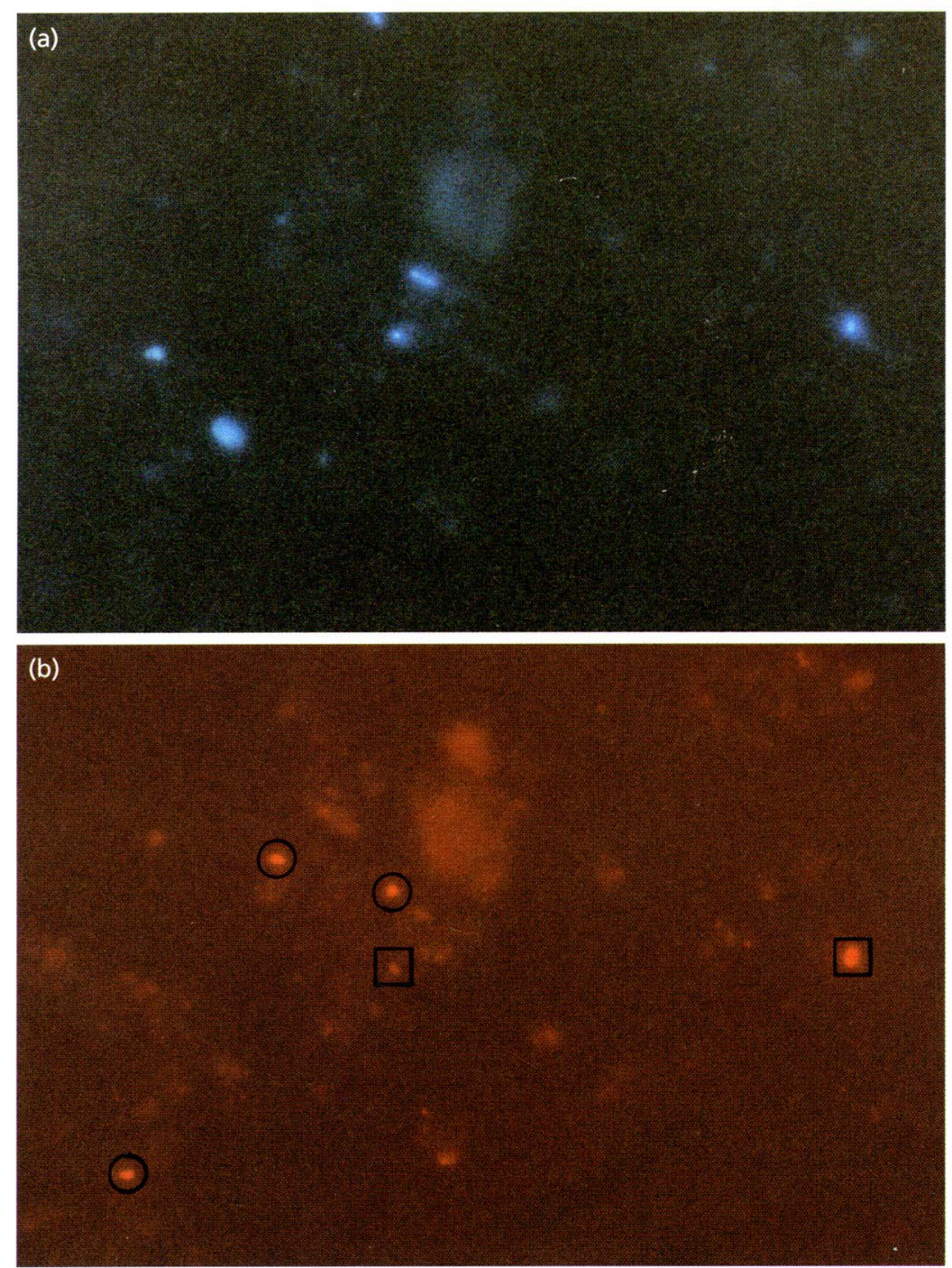

\begin{abstract}
Fig. 1. Dual-stained cells of a sample of seawater sediment suspension taken from a continuous culture; a comparison of the same microscopic field with Zeiss filter sets no. 01 and 15. (a) DAPI-stained cells appear bright blue. (b) In situ-hybridized cells determined with probe GAM42a appear red and are marked by squares, when simultaneously stained with DAPI. Cells which were hybridized but were not stained with DAPI are marked by circles. Only two of the six DAPI-stained cells hybridized with the probe GAM42a, which is specifically designed to detect members of the $\gamma$ Proteobacteria. Magnification $\times 700$.
\end{abstract}

cells (data not shown). Here the low recovery rate $(33.5 \%)$ is predominantly attributed to cell losses during the hybridization process.

\section{Standard deviation}

To determine the standard deviation of the in situ hybridization of cells in the sediment suspension we collected five parallel samples from a continuous culture at a dilution rate of $0.008 \mathrm{~h}^{-1}$. The samples were prepared separately and hybridized with all the probes listed in Table 1. Two replicates were examined per probe. The highest standard deviation $( \pm 8.3 \%)$ of the different probes was calculated for the CF319a probe. However, since the distribution of bacteria in the sediment suspension was not always completely homo- 


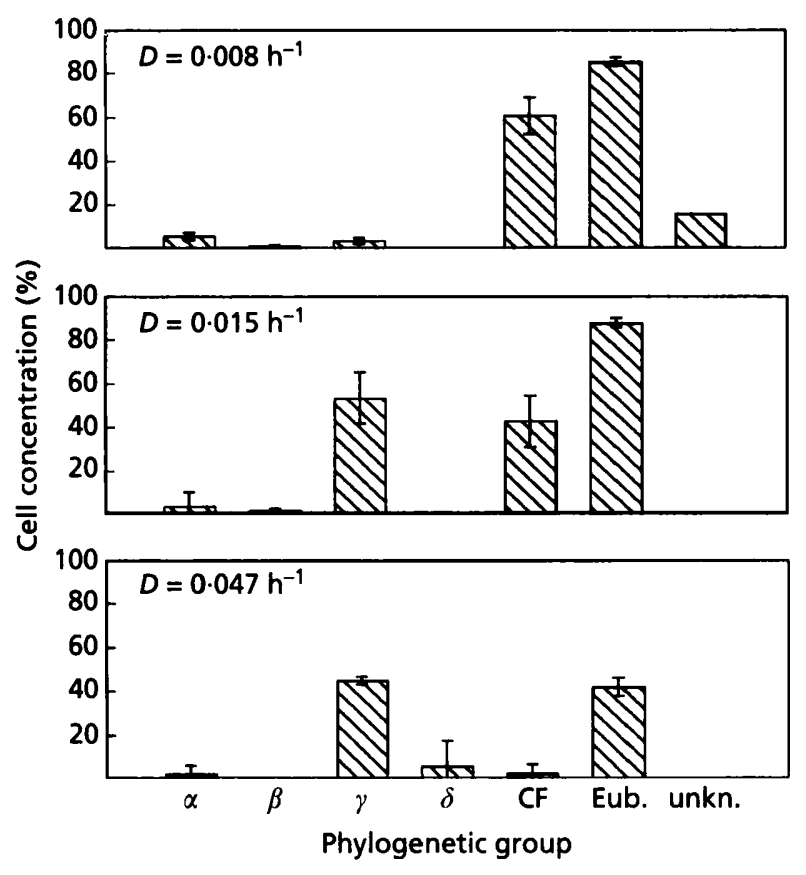

Fig. 2. Shift of the community structure of a continuous culture of seawater sediment suspension with an increasing dilution rate. Phylogenetic groups were determined by in situ hybridization. The amount of the unknown phylogenetic groups (unkn.) was calculated as the difference between the number of eubacteria and the sum of the other bacterial groups. The cell concentration is given as percentage of DAPIstained cells.

geneous and because cell numbers were only counted in two replicates, deviations of more than $8 \%$ between two replicates were also accepted. In few cases, a deviation of $20 \%$ between two replicates had to be tolerated. This was due to the inhomogeneity of the sediment suspension.

\section{Detection of bacteria in cultures of seawater sediment suspensions}

We successfully applied the in situ hybridization method to continuous cultures of the mud-flat-sediment suspensions and studied the changes in the community structure of the indigenous microbial population during the cultivation. The most critical problem, the autofluorescence of sediment particles, was dealt with by accepting only dual-stained cells (DAPI and Cy3labelled probes) as hybridized bacteria. Autofluorescent sediment particles could not be mistaken for hybridized cells because a sediment particle showed a weak grey colour when stained with DAPI at concentrations of $1 \mu \mathrm{g} \mathrm{ml}^{-1}$ in the $1: 1$ mixture with Dabco (Fig. 1). Using higher concentrations of DAPI, we observed weak yellow sediment particles as described by other authors (Porter \& Feig, 1980; Kapuscinski, 1995). With the low concentration of DAPI we obtained a dimmer background which made it easier to count the DAPI-stained cells.
Comparing DAPI-stained cells to cells labelled with specific rRNA-targeted probes, we sometimes observed cells which were hybridized with a probe but were not stained with DAPI (Fig. 1). As this phenomenon was also observed when higher DAPI concentrations were applied, we had to accept that occasionally a few bacteria were not stained by DAPI. Hybridizing a sample with the GAM42a probe and staining in parallel with DAPI showed the specificity of this probe. Only $33 \%$ of the DAPI-stained cells showed the red epifluorescence of the hybridized oligonucleotide probe GAM42a (compare Fig. 1a and b).

Taking samples at different dilution rates of the culture and hybridizing them with different group-specific oligonucleotide probes and staining them with DAPI, we could demonstrate that the mixed population showed a shift with the increase in dilution rate, from large amounts of Cytophaga/Flavobacteria $(60 \%$ of the population stained by DAPI at $\left.D=0.008 \mathrm{~h}^{-1}\right)$ to large numbers of members of the $\gamma$-Proteobacteria $(45 \%$ at $D=0.047 \mathrm{~h}^{-1}$ ) (Fig. 2). The culture conditions favoured the growth of the $\gamma$-Proteobacteria, whereas the Cytophaga/Flavobacteria were slowly washed out. The concentration of $\alpha$-, $\beta$ - and $\delta$-Proteobacteria was at the lower detection limit and ranged within the calculated standard deviation of the method. As the minimum detection limit of the method was $2.8 \times 10^{5}$ cells $\mathrm{ml}^{-1}$ (the concentration where only one cell was counted in the nine fields of the slide), it appeared to be a problem when minor fractions of the natural population, e.g. sulfate-reducing bacteria, only occurred at a concentration of about $10^{2}$ cells $\mathrm{ml}^{-1}$ [concentration verified with Austin's MPN method (1988) and the medium according to Cote \& Gherna (1994)]. Thus, only phylogenetic groups which could be found with more than $2 \cdot 8 \times 10^{5}$ cells $\mathrm{ml}^{-1}$ could be detected using this technique. The difference between the number of eubacteria and the sum of the other bacteria which were analysed with more specific probes (members of the $\alpha$-, $\beta$-, $\gamma$ - and $\delta$-Proteobacteria and of the Cytophaga/ Flavobacterium cluster) is depicted in Fig. 2 as unknown phylogenetic groups. The fact that the sum of the bacteria detected with specific probes (ALF1b, BET42a, GAM42a, SRB and CF319a) is sometimes higher than the bacteria cell numbers determined with the bacterial probe EUB338 (which includes these specific phylogenetic groups) could be explained by the standard deviation of this method.

\section{DISCUSSION}

We applied in situ hybridization with rRNA-targeted oligonucleotide probes to analyse the composition of the bacterial population of an intertidal sediment suspension in continuous-flow culture. First, we tested the recovery rate of spiked cells in the intertidal sediment suspension. Then we applied this method to determine the structure of the microbial community during the course of the cultures and compared the number of DAPI-stained cells with the number of fluorescently 
labelled cells. The signals obtained with the different probes were specific to the cells of each corresponding phylogenetic group. Non-specific binding of the probes to the sediment was not observed.

As the culture was run as an enrichment culture and as our aim was to analyse the population structure of the culture in parallel with growth, we had to hybridize the samples immediately after they were taken from the bioreactor. Samples were not divided into separate quantities to be treated individually; thus we set up hybridization conditions which were optimal for the majority, but not for all, of the probes used.

Non-optimal signals were obtained only with the ALF1b probe, which gave a weak (Rhodospirillum rubrum) or moderate (Rhodopseudomonas palustris) fluorescent signal. This was due to the high concentration of formamide $(35 \%)$ in our hybridization buffer. It was interesting that the fluorescent signal of the probe EUB338, which was obtained under the same conditions as probe ALF1b, was very strong, although Manz et al. (1992) had recommended $20 \%$ formamide in the hybridization buffer for both probes. The high hybridization efficiency of the EUB338 probe may be due to the complex association of the 16S rRNA target molecule with ribosomal proteins (Frischer et al., 1996) or RNA-RNA interactions (Amann et al., 1995). As a consequence of the weak to moderate signal of the ALF1b probe we could not conclude that cells of a mixed population giving a weak fluorescent signal with the ALF1b probe were of limited activity, as was described by DeLong et al. (1989) and Wallner et al. (1993), who outlined the correlation between the amount of ribosomes (corresponding to the amount of target regions) and the growth rate. However, it is possible to use the fluorescent intensity obtained with the other probes as a marker for the physiological activity of the cells in their natural habitat under defined conditions. We observed consistently intense fluorescent signals with all probes. This was the case for all samples taken at the different dilution rates of the cultures $(D=$ $\left.0.008-0.047 \mathrm{~h}^{-1}\right)$. Since the sole carbon source, hexadecane, and an increase in the dilution rates work as selective factors, only actively growing cells, which have high amounts of RNA and hence give good fluorescent signals, remained in the continuous culture. The results showed that under the given culture conditions the $\gamma$ Proteobacteria were favoured, whereas the Cytophaga/ Flavobacterium group was suppressed. Obviously the $\gamma$ Proteobacteria enjoy better conditions for growth in an aerobic culture with hexadecane as a carbon source, whereas in the undisturbed, pristine mud flat (before adding to the continuous culture) and at low dilution rates the Cytophaga/Flavobacterium group is significantly more dominant. A number of hexadecanedegrading bacteria, isolated by traditional methods, are mentioned in the literature (Radwan \& Sorkoh, 1993). Many of them are $\gamma$-Proteobacteria. Therefore one could come to the conclusion that the $\gamma$-Proteobacteria are generally favoured by hexadecane. This conclusion is not necessarily right, because the enumeration of bac- teria by in situ hybridization is due to different selectivity mechanisms not comparable to traditional isolation on selective media.

The recovery of defined numbers of cells introduced into a sterile sediment suspension indicates that the method of in situ hybridization described is applicable to cultures of seawater sediment suspensions. Moreover, it shows the detection of specific target organisms against a background of non-target organisms, e.g. $34.5 \%$ of the $\alpha$-Proteobacterium Rhodospirillum rubrum, were detected against a background of $65.5 \%$ of the two other phylogenetic groups ( $\beta$ - and $\delta$-Proteobacteria) in the sediment suspension. Comparable results were published by Hahn et al. (1992). This latter authors recovered $6-68 \%$ of Pseudomonas aeruginosa cells introduced into different sterile soil samples and attributed these varying recovery rates to the different kinds of soil samples examined. By contrast, the low rates of recovery in our investigation may be due to a wash-off of cells and sediment during the hybridization procedure, e.g. during the series of ethanol baths and washing. It is recommended to avoid cell losses by binding them to gelatin-coated slides (Amann et al., 1990a), but in our study we observed a wash-off of cells from pure cultures and a wash-off of the sediment even when applied to gelatin-coated slides. However, one can assume that the wash-off is not a selective process and thus the relative proportion of the phylogenetic groups has always been the same. Additionally, not all cells were in a high state of activity (the cells were harvested in the early stationary phase of growth) and this explains why the defined cell numbers (determined by DAPI staining) could not be recovered completely by in situ hybridization with the specific probes (Table 3).

Amann et al. (1995) stressed the importance of fixation procedures as an integral part of in situ hybridization, but our experiments produced good hybridization results without a previous fixation. Other authors (Hicks et al., 1992; DeLong et al., 1989) found that most cultured bacterial cells seemed to be entirely permeable to oligonucleotide probes of the size used in this study.

Hahn et al. (1992) described the autofluorescence of soil components as a potential problem of the in situ hybridization technique applied to soil samples. We tackled the problem of sediment particle autofluorescence by accepting only dual-stained cells (DAPI and Cy3-labelled probes) as hybridized bacteria. Thus in dual-stained samples, red autofluorescent sediment particles could not be mistaken for hybridized cells because a sediment particle appeared grey when observed by a Zeiss filter set 01 . The fact that DAPI, as a DNA-specific dye, cannot be used to differentiate between living and dead bacteria, since DNA is also stained in non-viable cells (Coleman, 1980), did not present any difficulties in this study, because non-viable cells cannot be hybridized. However, the concentration of viable bacteria was overestimated, since the total number of bacteria also included dead cells. 
The phenomenon of bacterial cells hybridized with Cy3labelled probes showing a weak, almost undetectable DAPI fluorescence (Fig. 1) was also found by E. LlobetBrossa, R. Rossello-Mora \& R. Amann (personal communication). They could, however, demonstrate binding of DAPI to the hybridized cells by taking micrographs with high-quality microscopes. A possible explanation for this phenomenon is that DAPI binds poorly to DNA in the high salt concentrations (Zweifel \& Hagström, 1995) which occur naturally in samples of the mud flat. In marine microbiology, the DAPI staining method requires formaldehyde-fixed cells (Porter \& Feig, 1980) - which were not used in this study - to avoid the negative effect of a high salt concentration. An alternative interpretation is that there may be cells containing small amounts of DNA or a genome with a few adenine and thymine regions (the favoured binding regions of DAPI) and that DAPI could therefore only bind to a lesser extent.

We conclude that the technique of in situ hybridization is suitable for the analysis of the population structures in the sediment suspension cultures we used. The transfer of our procedure of the analysis of natural bacterial communities to other types of sediments is, moreover, crucial as more research is needed. A limitation of the in situ detection method applied to natural populations is caused by the minimum detection limit of $2.8 \times 10^{5}$ cells $\mathrm{ml}^{-1}$. Some phylogenetic groups, in our example the $\beta$ and $\delta$-Proteobacteria, exist in natural habitats at a concentration much lower than $10^{5}$ cells $\mathrm{ml}^{-1}$. These bacterial groups which occur only in small concentrations would be neglected, since it is impossible to get them at sufficient concentrations in a sample of sediment suspension to optimize this method and to achieve the best possible in situ detection of all phylogenetic groups. In our particular case, we analysed a highly active population with a high cell concentration (DAPIcounted concentrations $2-4 \times 10^{8}$ cells ml ${ }^{-1}$ ). However, in natural environments, the concentrations of bacteria which are in a transient state between viability and death may be considerable (Roszak \& Colwell, 1987). Furthermore, the sediment suspension used in this approach was fairly homogeneous and fine-grained, with grain size distribution from 0.6 to $<0.002 \mathrm{~mm}$. In other soil environments the analysis of population structures may be particularly difficult due to the heterogeneity and complexity of the soil system (Ritz \& Griffiths, 1994).

\section{ACKNOWLEDGEMENTS}

This work was supported by the Umweltforschungszentrum Leipzig-Halle. We thank Dr Jörg Overmann and Dr Thomas Gorontzy for the reference strains and PD Dr Rudolf Amann for helpful discussion.

\section{REFERENCES}

Amann, R. I., Krumholz, L. \& Stahl, D. A. (1990a). Fluorescentoligonucleotide probing of whole cells for determinative, phylogenetic, and environmental studies in microbiology. J Bacteriol $172,762-770$.
Amann, R. I., Binder, B. J., Olson, R. J., Chrisholm, S. W., Devereux, R. \& Stahl, D. A. (1990b). Combination of 16 S rRNAtargeted oligonucleotide probes with flow cytometry for analyzing mixed microbial populations. Appl Environ Microbiol 56, 1919-1925.

Amann, R. I., Springer, N., Ludwig, W., Görtz, H.-D. \& Schleifer, K.-H. (1991). Identification in situ and phylogeny of uncultured bacterial endosymbionts. Nature 351, 161-164.

Amann, R. I., Ludwig, W. \& Schleifer, K.-H. (1995). Phylogenetic identification and in situ detection of individual microbial cells without cultivation. Microbiol Rev 59, 143-169.

Austin, B. (1988). Methods in Aquatic Bacteriology. New York: Wiley.

Berthe-Corti, L., Bruns, A. \& Hulsch, R. (1997). Semi-continuousflow cultures with marine sediment suspensions containing nonpolar carbon sources - culture control by a pneumatic sediment suspension dosage system. J Microbiol Methods 29, 129-137.

Brosius, J., Dull, T. J., Sleeter, D. D. \& Noller, H. F. (1981). Gene organisation and primary structure of a ribosomal RNA operon from Escherichia coli. J Mol Biol 148, 107-127.

Coleman, A. W. (1980). Enhanced detection of bacteria in natural environments by fluorochrome staining of DNA. Limnol Oceanogr 25, 948-951.

Cote, R. J. \& Gherna, R. L. (1994). Nutrition and media. In Methods for General and Molecular Bacteriology, pp. 155-178. Edited by P. Gerhardt, R. G. E. Murray, W. A. Wood \& N. R. Krieg. Washington, DC: American Society for Microbiology.

DeLong, E. F., Wickham, G. S. \& Pace, N. R. (1989). Phylogenetic stains: ribosomal RNA-based probes for the identification of single microbial cells. Science 243, 924-934.

Fredrickson, J. K., Balkwill, D. L., Zachara, J. M., Li, S.-M. W., Brockman, F. J. \& Simmons, M. A. (1991). Physiological diversity and distributions of heterotrophic bacteria in deep cretaceous sediments of the Atlantic coastal plain. Appl Environ Microbiol 57, 402-411.

Frischer, M. E., Floriani, P. J. \& Nierzwicki-Bauer, S. A. (1996). Differential sensitivity of $16 \mathrm{~S}$ rRNA targeted oligonucleotide probes used for fluorescence in situ hybridization is a result of ribosomal higher order structure. Can J Microbiol 42, 1061-1071.

Grasshoff, K. (1983). Methods of Seawater Analysis. Weinheim: Verlag Chemie.

Hahn, D., Amann, R. I., Ludwig, W., Akkermans, A. D. L. \& Schleifer, K.-H. (1992). Detection of micro-organisms in soil after in situ hybridization with rRNA-targeted, fluorescently labelled oligonucleotides. J Gen Microbiol 138, 879-887.

Hicks, R. E., Amann, R. I. \& Stahl, D. A. (1992). Dual staining of natural bacterioplankton with 4',6-diamidino-2-phenylindole and fluorescent oligonucleotide probes targeting kingdom-level $16 \mathrm{~S}$ rRNA sequences. Appl Environ Microbiol 58, 2158-2163.

Kapuscinski, J. (1995). DAPI : a DNA-specific fluorescent probe. Biotech Histochem 70, 220-233.

Leahy, J. G. \& Colwell, R. R. (1990). Microbial degradation of hydrocarbons in the environment. Microbiol Rev 54, 305-315.

Manz, W., Amann, R., Ludwig, W., Wagner, M. \& Schleifer, K.-H. (1992). Phylogenetic oligodeoxynucleotide probes for the major subclasses of Proteobacteria : problems and solutions. Syst Appl Microbiol 15, 593-600.

McKay, A. M. (1992). Viable but non-culturable forms of potentially pathogenic bacteria in water. Lett Appl Microbiol 14, 129-135. 
Manz, W., Wagner, M., Amann, R. \& Schleifer, K.-H. (1994). In situ characterization of the microbial consortia active in two wastewater treatment plants. Water Res 28, 1715-1723.

Manz, W., Amann, R., Ludwig, W., Vancanneyt, M. \& Schleifer, K.-H. (1996). Application of a suite of 16S rRNA-specific oligonucleotide probes designed to investigate bacteria of the phylum cytophaga-flavobacter-bacteroides in the natural environment. Microbiology 142, 1097-1106.

Oliver, J. D. \& Colwell, R. R. (1973). Extractable lipids of gramnegative marine bacteria: fatty acid composition. Int $J$ Syst Bacteriol 23, 442-458.

Porter, K. G. \& Feig, Y. S. (1980). The use of DAPI for identifying and counting aquatic microflora. Limnol Oceanogr 25, 943-945.

Radwan, S. S. \& Sorkhoh, N. A. (1993). Lipids of n-alkane-utilizing microorganisms and their application potential. $A d v A p p l$ Microbiol 39, 29-90.

Ritz, K. \& Griffiths, B.S. (1994). Potential application of a community hybridization technique for assessing changes in the population structure of soil microbial communities. Soil Biol Biochem 26, 963-971.

Roszak, D. B. \& Colwell, R. R. (1987). Survival strategies of bacteria in the natural environment. Microbiol Rev 51, 365-379.

Ruger, H.-J. \& Krambeck, H.-J. (1994). Evaluation of the Biolog substrate metabolism system for classification of marine bacteria. Syst Appl Microbiol 17, 281-288.

Snaidr, J., Amann, R., Huber, I., Ludwig, W. \& Schleifer, K.-H. (1997). Phylogenetic analysis and in situ identification of bacteria in activated sludge. Appl Environ Microbiol 63, 2884-2896.

Spring, S., Amann, R., Ludwig, W., Schleifer, K.-H. \& Petersen, N. (1992). Phylogeneric diversity and identification of nonculturable magnetotactic bacteria. Syst Appl Microbiol 15, 116-122.
Staley, J. T. \& Konopka, A. (1985). Measurement of in situ activities of nonphotosynthetic microorganisms in aquatic and terrestrial habitats. Annu Rev Microbiol 39, 321-346.

Wagner, M., Amann, R., Lemmer, H. \& Schleifer, K.-H. (1993). Probing activated sludge with oligonucleotides specific for Proteobacteria: inadequacy of culture-dependent methods for describing microbial community structure. Appl Environ Microbiol 59, 1520-1525.

Wagner, M., Amann, R., Kămpfer, P., Assmus, B., Hartmann, A., Hutzler, P., Springer, N. \& Schleifer, K.-H. (1994). Identification and in situ detection of gram-negative filamentous bacteria in activated sludge. Syst Appl Microbiol 17, 405-417.

Wallner, G. \& Amann, R. (1993). Fluorescence in situ hybridization for the detection and identification of microbial cells by fluorescence microscopy and flow cytometry. In Ribosomal RNAtargeted Oligonucleotide Probes. Workshop on Water Microbiology for the 21st Century, 21-22 September, MacQuarie University, pp. 1-12.

Wallner, G., Amann, R. \& Beisker, W. (1993). Optimizing fluorescent in situ hybridization with rRNA-targeted oligonucleotide probes for flow cytometric identification of microorganisms. Cytometry 14, 136-143.

Ward, D. M., Weller, R. \& Bateson, M. M. (1990). 16S rRNA sequences reveal numerous uncultured microorganisms in a natural community. Nature 345, 63-65.

Zweifel, U. L. \& Hagström, A. (1995). Total counts of marine bacteria include a large fraction of non-nucleoid-containing bacteria (ghosts). Appl Environ Microbiol 61, 2180-2185.

Received 18 February 1998; revised 27 May 1998; accepted 4 June 1998. 